\title{
Decontamination of respirators amid shortages due to SARS-CoV-2
}

\author{
Ravinder Thaper ${ }^{1} \cdot$ Brendan Fagen $^{1} \cdot$ Jonghwa $^{2}{ }^{2}$ (I) \\ Received: 26 November 2020 / Accepted: 31 May 2021 / Published online: 12 June 2021 \\ (c) The Author(s), under exclusive licence to European Photochemistry Association, European Society for Photobiology 2021
}

\begin{abstract}
The pandemic created by SARS-CoV-2 has caused a shortage in the supplies of N95 filtering facepiece respirators (FFRs), disposable respirators with at least $95 \%$ efficiency to remove non-oily airborne particles, due to increasing cases all over the world. The current article reviewed various possible decontamination methods for FFR reuse including ultraviolet germicidal irradiation (UVGI), hydrogen peroxide vapor (HPV), microwave-generated steam (MGS), hydrogen peroxide gas plasma (HPGP), and 70\% or higher ethanol solution. HPV decontamination was effective against bacterial spores $\left(6 \log _{10}\right.$ reduction of Geobacillus stearothermophilus spores) on FFRs and viruses ( $>4 \log _{10}$ reduction of various types of viruses) on inanimate surfaces, and no degradation of respirator materials and fit has been reported. 70\% or higher ethanol decontamination showed high efficacy in inactivation of coronaviruses on inanimate surfaces $\left(>3.9 \log _{10}\right.$ reduction) but it was lower on FFRs which filtration efficiency was also decreased. UVGI method had good biocidal efficacy on FFRs ( $>3 \log _{10}$ reduction of H1N1 virus) combined with inexpensive, readily available equipment; however, it was more time-consuming to ensure sufficient

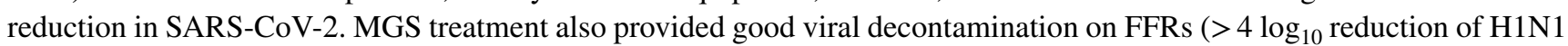
virus) along with less time-intensive process and readily available equipment while inconsistent disinfection on the treated surfaces and deterioration of nose cushion of FFRs were observed. HPGP was a good virucidal system $\left(>6 \log _{10}\right.$ reduction of Vesicular stomatitis virus) but filtration efficiency after decontamination was inconsistent. Overall, HPV appeared to be one of the most promising methods based on the high biocidal efficacy on FFRs, preservation of respirator performance after multiple cycles, and no residual chemical toxicity. Nonetheless, equipment cost and time of the HPV process and a suitable operating room need to be considered.
\end{abstract}

Keywords Decontamination $\cdot$ Hydrogen peroxide vapor (HPV) $\cdot$ Filtering facepiece respirator (FFR) $\cdot$ N95 $\cdot$ COVID-19

\section{Introduction}

SARS-CoV-2 (Severe Acute Respiratory Syndrome-Coronavirus-2) or COVID-19 (Coronavirus Disease 2019) is an infectious disease caused by a virus in the family of coronaviruses which usually causes respiratory illness in humans $[1,2]$. The novel coronavirus spreads rapidly from person to person, and its basic reproductive number $\left(R_{0}\right)$ was estimated to be 5.7 in Wuhan, China [3]. SARS-CoV-2 originated in Wuhan, Hubei province, China in November of 2019, and

Jonghwa Oh

jonghwa@uab.edu

1 Samuel Ginn College of Engineering, Auburn University, Auburn, AL 36849, USA

2 Department of Environmental Health Sciences, University of Alabama at Birmingham, Birmingham, AL 35294-0022, USA has quickly spread around the world to become a pandemic as defined by the World Health Organization (WHO). The virus is primarily transmitted through the inhalation of respiratory aerosols/droplets that are exhaled by an infected person while in close contact. Infection may occur due to contact with a contaminated surface and subsequently touching one's face, eyes, or mouth [4]. The major symptoms of illness caused by SARS-CoV-2 are sore throat, cough, fever, chills, difficulty breathing or shortness of breath, repeated shaking with chills, muscle pain, and loss of taste or smell $[5,6]$. On January 20, 2020, the first case of SARS-CoV-2 in the United States was confirmed in Snohomish County, in the state of Washington from a 35-year-old man who traveled to Wuhan, China [7]. SARS-CoV-2 has a case fatality rate (CFR referring to the number of deaths due to the virus divided by confirmed cases recorded by world governments) of $1.70 \%$ in the United States of America, and CFR numbers range anywhere from $1.0 \%$ (Turkey) to $8.7 \%$ (Mexico) as of 
January 15, 2021 [8]. It is likely to have an infection fatality rate (IFR referring to the number of deaths due to the virus divided by total infections) between 0.08 and $1.26 \%$ depending on the country and age distribution of their population, as per data from the Johns Hopkins Coronavirus Resource Center [8].

A respirator is personal protective equipment (PPE) which covers the nose and mouth or the entire face or head to protect the wearer from inhaling harmful atmospheric contaminants [9]. Air-purifying respirator (APR) is a type of respirators which use filters or cartridges to remove contaminants from the air-breathed, filters for protection against particulates and cartridges for protection against gases/vapors. Two main types of APRs are particulate respirators and chemical cartridge respirators. Filtering facepiece respirator (FFR) is the type of particulate respirators with a filter as an integral part of the facepiece or with the entire facepiece composed of the filtering medium $[10,11]$. The National Institute for Occupational Safety and Health (NIOSH) tests, approves, and certifies respirators. There are three series of resistance to filter efficiency degradation, N-, R-, and P-series, and three levels of filtration efficiency, 95, 99, and 99.97\% [12]. N-, R-, and P-series filters are designed to protect against free of oil aerosols, oil-based liquid aerosols for limited time, and oil-based liquid aerosols, respectively [12]. $\mathrm{N}$-series filters are tested with sodium chloride $(\mathrm{NaCl})$ with a count median diameter (CMD) of $0.075 \pm 0.02 \mu \mathrm{m}$ and a geometric standard deviation (GSD) not exceeding 1.86 [13]. Thus, N95 FFRs are at least 95\% efficient to remove non-oily aerosols under the NIOSH test conditions stated in the 42 Code of Federal Regulations (CFR) Part 84. N95 FFRs are considered as tight-fitting respirators which make a tight seal between the respirator and user's face. The Occupational Safety and Health Administration (OSHA) mandates employers to ensure that employees who use tightfitting facepiece respirators under respiratory protection program pass fit testing unless they are under voluntary use conditions, and even in those cases it is recommended to be fit tested [14].

Surgical masks are devices which cover the wearer's nose and mouth and provide a physical barrier to fluids and particulates [15]. Manufacturers of surgical masks test their product to obtain clearance by the Food and Drug Administration (FDA) [15] and the masks are tested using a biological organism aerosol (i.e., Staphylococcus aureus) and a $0.1 \mu \mathrm{m}$ latex sphere aerosol in accordance with American Society for Testing and Materials (ASTM) standards F2101 and F2299 [16]. Surgical masks have lower filtration efficiency for small particles mainly due to the lower filtration requirements. Further, loose-fitting facepieces including surgical masks lower the degree of protection due to leakage around the edges. In the context of an influenza pandemic, health care workers $(\mathrm{HCWs})$ are recommended to wear surgical N95 FFRs for protection against bodily fluids, with the added benefits of high filtration efficiency and tight fit from NIOSH certified N95 FFRs [16]. Additional face shields may provide extra protection from droplets/aerosols directly expelled at the HCW but are not required.

At present, FFRs are considered one-time use products (i.e. disposable) and there is no manufacturer authorized method for decontamination before reuse [17]. The CDC estimated that HCWs may require 90 million N95 respirators in the U.S. if a pandemic last for 42 days [16]. During the 2009 H1N1 influenza pandemic, the CDC Influenza Interim Guidance document acknowledged N95 supply shortages [18]. Under the current SARS-CoV-2 pandemic, many American hospitals have experienced widespread PPE shortages, including respirators [19]. Therefore, reuse of FFRs during a pandemic could be a viable solution to the respirator shortage. Various decontamination techniques have been examined, however, there are few review articles which outline different types of decontamination methods for reuse of disposable respirators. Rubio-Romero et al. performed a literature review on several decontamination methods of FFRs, but a systematic review on respirator performance, such as filtration efficiency and fit testing is lacking, along with practical factors, such as time and cost [20]. NIOSH addressed that vaporous hydrogen peroxide, ultraviolet germicidal irradiation, and moist heat are shown the most promising methods of FFR decontamination but no details are available on the webpage [17]. In this article, we outlined various decontamination methods for the application of disposable N95 type FFRs based on the literature available with two purposes: first, to identify/summarize common decontamination methods, and second, to determine more efficient method(s) based on the determinant factors for overall performance including decontamination efficacy, respirator function, and feasibility.

\section{Methods}

Literature review was conducted on peer-reviewed publications to identify different types of decontamination methods in which antimicrobial efficiency had been tested primarily with N95 type FFRs, using key words "decontamination", "filtering facepiece respirator (FFR)", and "respirator," as well as variants of "COVID-19" and "SARS-CoV-2." There were two main classifications of decontamination methods, chemical and physical. The chemical methods found were soapy water, bleach, liquid hydrogen peroxide, isopropyl alcohol, ethylene oxide, hydrogen peroxide vapor (HPV), vaporized hydrogen peroxide (VHP) or hydrogen peroxide gas plasma (HPGP), ozone solution, and disinfectant wipes. The physical methods were autoclave, dry heat, ultraviolet germicidal irradiation (UVGI), microwave radiation, 
microwave-generated steam (MGS), and moist heat. The first step was to choose common decontamination methods. Different types of decontamination methods were examined for their biocidal efficacy in at least two studies. The second step of the study was to review the performance of decontamination methods in terms of antimicrobial efficacy, residual chemical hazards, post-decontamination filtration efficiency, post-decontamination physical integrity, availability of equipment and time for decontamination, and, if available, the cost of decontamination equipment.

\section{Results and discussion}

Table 1 summarizes decontamination methods on biocidal efficacy identified in the present review and Table 2 summarizes the effects of various decontamination methods on filtration efficiency, physical integrity, and residual chemical hazards. Five most common decontamination methods selected were ethanol, ultraviolet irradiation (UVGI), microwave-generated steam (MGS), hydrogen peroxide vapor (HPV), and hydrogen peroxide gas plasma (HPGP) and each method is discussed in detail below.

\subsection{Ethanol}

Severe acute respiratory syndrome coronavirus (SARS-CoV) and Middle East respiratory syndrome coronavirus (MERS$\mathrm{CoV}$ ) have been effectively inactivated by $70 \%, 78 \%, 80 \%$, $85 \%$, and $95 \%$ ethanol solutions (i.e., suspension tests) and all concentrations resulted in a $\log _{10}$ reduction of viral infectivity of 3.9 or above [32-36]. Lin et al. performed a study examining filtration efficiency of electret masks including N95 FFRs after multiple different decontamination methods [42]. The authors observed that treatment of electret masks with ethanol or with isopropanol increased the penetration of particles which was probably because the electrostatic charge on the filters was eliminated; fiber diameter, packing density, and charge density ultimately determine the effect on filtration $[42,43]$. Lin et al. found that $70 \%$ ethanol decontamination increased the penetration of both $75 \mathrm{~nm}$ and $300 \mathrm{~nm}$ particles through the masks and the most penetrating particle size (MPS) of N95 FFRs increased upon decontamination with ethanol, indicating reduced filtration efficiency [42]. Lin et al. also found that pressure dropped in all examined electret masks after ethanol decontamination. In another study, they examined the relative survival (RS) of Bacillus subtilis spores on N95 FFRs under worstcase temperature and relative humidity conditions and $70 \%$ ethanol resulted in $22 \%$ of RS in $24 \mathrm{~h}$ which was decayed from the initial RS of $73 \%$ [23]. The conclusion that may be drawn from the results of the studies above is that ethanol decontamination can effectively inactivate coronavirus on inanimate surfaces, but when applied to FFRs, it may lower biocidal efficacy and degrade the filter quality. Ethanol decontamination requires more studies to confirm effectiveness in decontaminating respirators as well as impact on FFR materials.

\subsection{Ultraviolet germicidal irradiation (UVGI)}

UVGI involves the use of $254 \mathrm{~nm}$ UV light, using a readily available 55-W source [44]. The main benefit of using UVGI is that a portable chamber can be created to disinfect respirators of HCWs at the hospital or care center, rather than shipping contaminated PPE to a central location for decontamination. The materials for the chamber, according to Donat [44], cost approximately $\$ 400$ for the bulbs and lamps and approximately $\$ 420$ for the Reflectix aluminized insulation. These easy to find components may be purchased at many generic hardware stores. The UVGI treatment of influenza virus on FFRs has shown $\geq 3 \log _{10}$ reduction and $4 \log _{10}$ reduction for $\mathrm{H} 1 \mathrm{~N} 1$ and $\mathrm{H} 5 \mathrm{~N} 1$, respectively [21, 22, 24]. In a Fischer et al.'s study, the UVC decontamination procedure inactivated SARS-CoV-2 more slowly on N95 fabric than on steel due to the nature of the material's weave; the material was too porous to be quickly decontaminated [45]. Although UVC decontamination may be less expensive and easy to set up, it may not be the best method of decontamination due to the time it would take to remove all possible contamination from the PPE. Studies have found that certain decontamination methods and procedures degraded respirators to the point of it being ineffective after even one or two rounds of decontamination, but UV-treated N95 FFRs, along with vaporous hydrogen peroxide (VHP) treated FFRs, maintained acceptable filtration efficiency after three rounds of decontamination [45].

\subsection{Microwave-generated steam (MGS)}

This process involves the use of microwave radiation to generate heat for the decontamination process. MGS is one of the least time-intensive methods and readily available [22]. It has been found that this process provides $>3 \log _{10}$ reduction and $>4 \log _{10}$ reduction in inactivation of bacteriophage MS2 and H1N1 influenza virus on FFRs, respectively [22, 26]. Furthermore, minimal degradation in filtration efficiency was found after disinfection of FFRs using microwave steam bags, and performance of the FFRs after MGS decontamination was maintained at 42 CFR 84 requirements when fit tested [26, 46]. However, in the Heimbuch et al.'s study, sporadic viable viruses were detected on FFRs after MGS treatment as well as after UVGI treatment [22]. FFR samples showed partial separation of the inner foam nose cushion after MGS treatment [46]. In addition, studies address the 


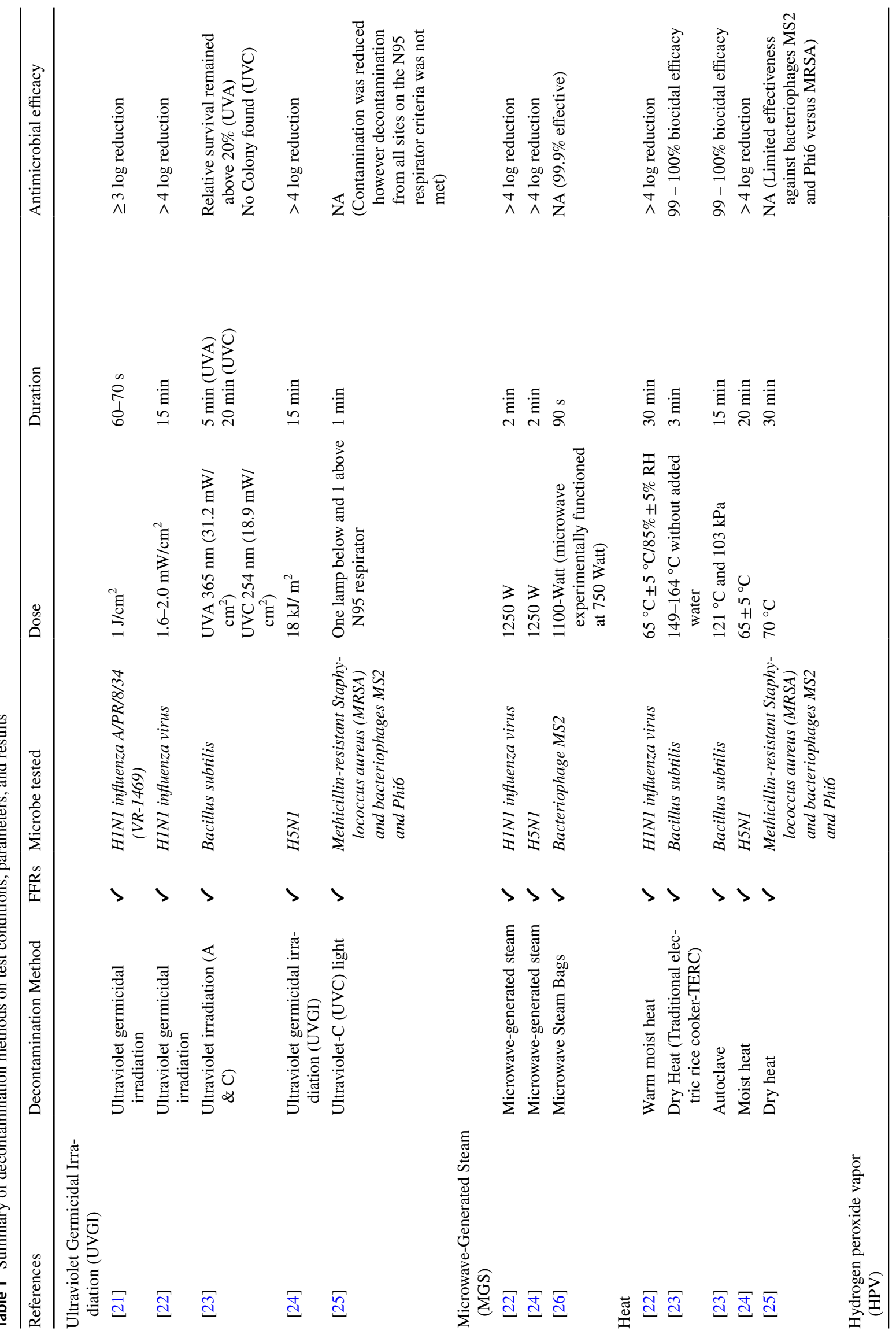




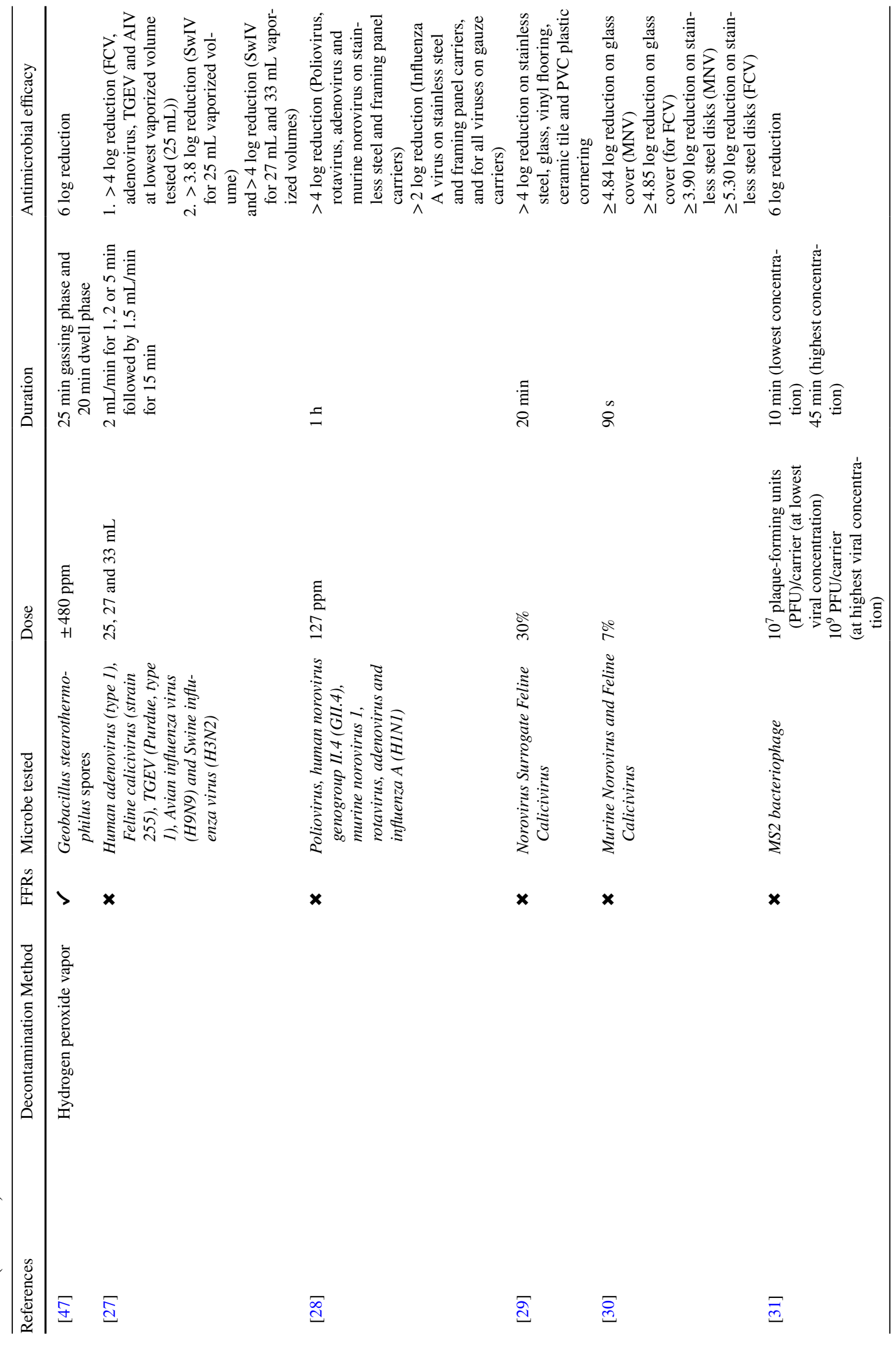




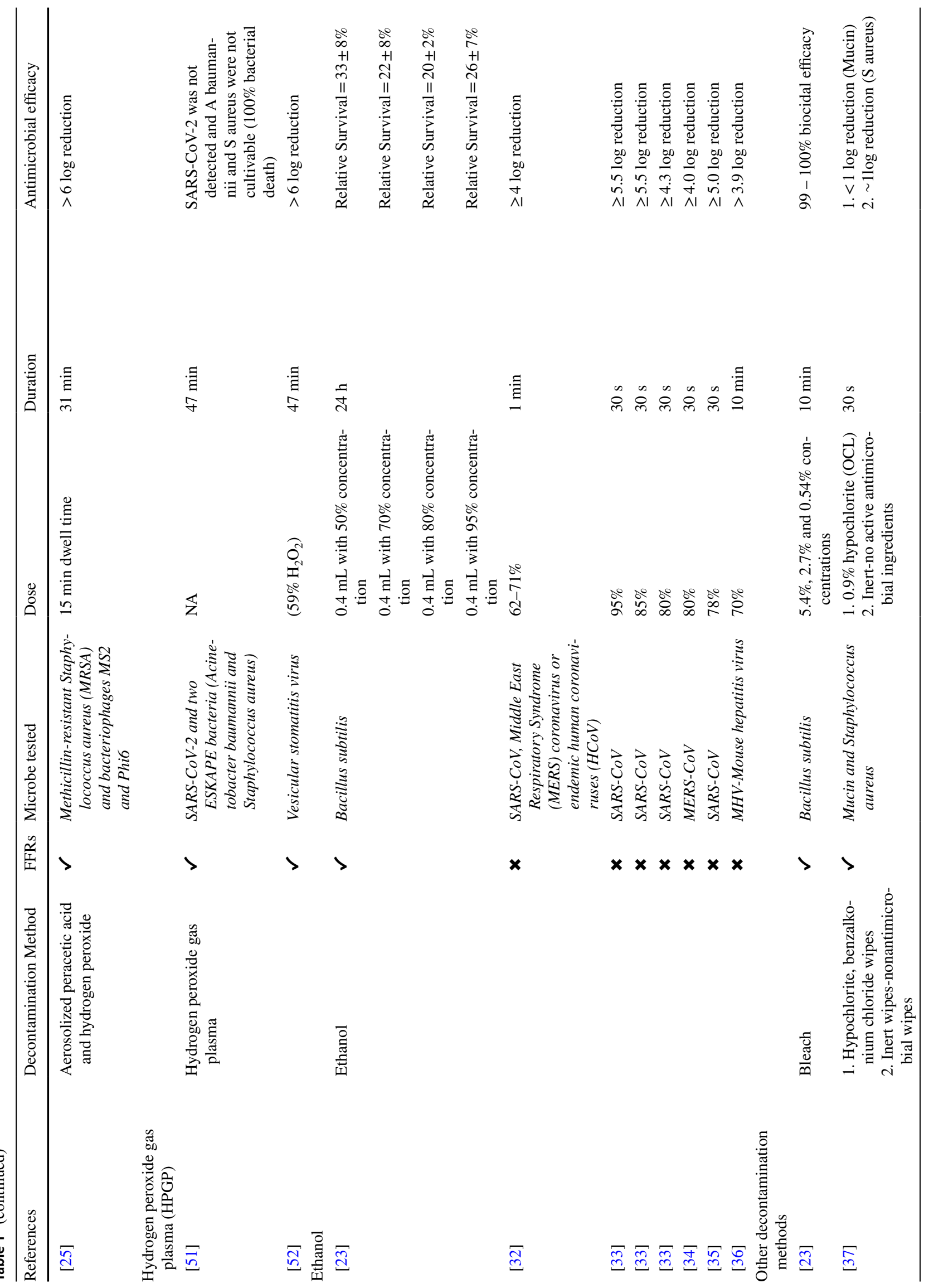




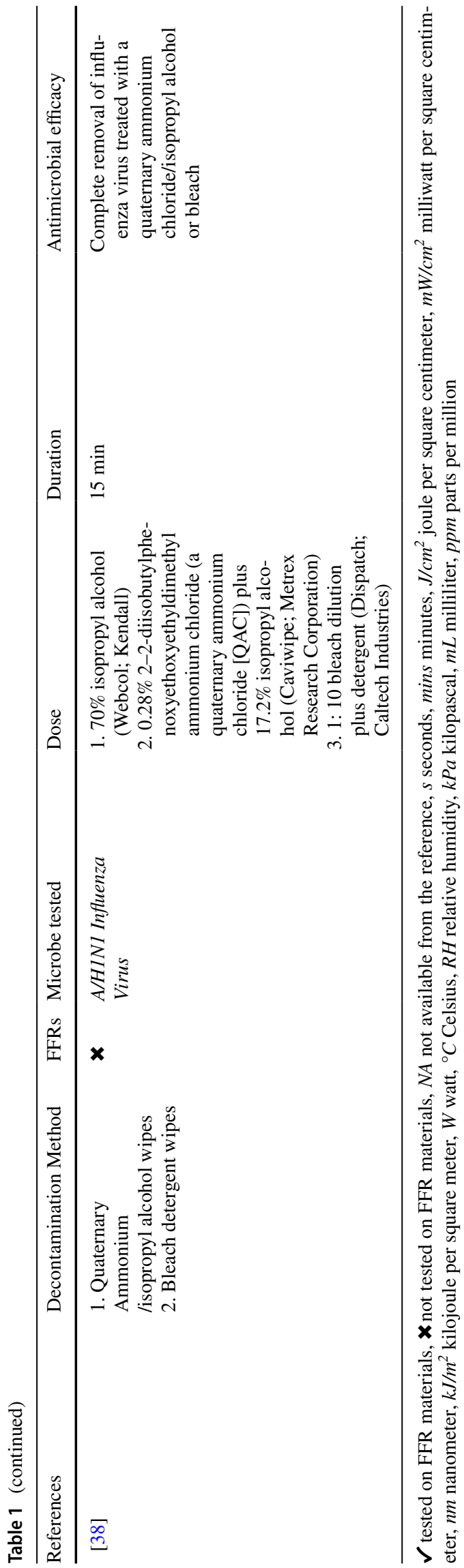

concern that the metallic noseband of FFRs would generate combustion when using dry microwave irradiation [24, 40].

\subsection{Hydrogen peroxide vapor (HPV)}

Two technologies using $\mathrm{H}_{2} \mathrm{O}_{2}$ vapor are condensing and non-condensing; condensing technology is called hydrogen peroxide vapor (HPV) and non-condensing technology is termed vaporized hydrogen peroxide vapor (VHP) [27]. HPV decontamination is conducted by saturating a disinfection chamber. This process has achieved biocidal efficacy of $6 \log _{10}$ reduction for the decontamination of N95 FFRs using Geobacillus stearothermophilus spores [47]. The four major steps in the process are chamber conditioning, gassing, dwell (i.e., contact phase), and $\mathrm{H}_{2} \mathrm{O}_{2}$ aeration [48]. These four steps can take up to several hours depending on the procedure employed and other researchers have tested this process for a duration ranging from a few minutes to an hour on various inanimate surfaces. On inanimate surfaces commonly found in a hospital setting, such as stainless steel, glass, and ceramic tile, $>4 \log _{10}$ reduction of feline calicivirus (FCV), human adenovirus type 1 , transmissible gastroenteritis coronavirus (TGEV), avian influenza virus (AIV), poliovirus, rotavirus, and murine norovirus 1 was reported [27-29]. $\mathrm{H}_{2} \mathrm{O}_{2}$ off-gassing testing and fit testing of N95 FFRs were conducted by Schwartz et al. and neither off-gassing nor loss of fit was found after the HPV decontamination process [47]. The authors reported that N95 respirators can still meet performance requirements after 50 times of decontamination with HPV. In another study by Kenney et al., a single HPV cycle completely eradicated the phage used as a proxy for SARS-CoV-2 from N95 respirators, with a limit of detection lower than the infectious dose of the majority of respiratory viruses [49]. FDA has granted several decontamination systems using HVP an emergency use authorization (EUA) for FFRs. While the VHP is a notouch automated technology in which operator errors are minimized [27], considerations regarding equipment cost, entire process time, and locating a suitable operating room need to be made.

\subsection{Hydrogen peroxide gas plasma (HPGP)}

Sufficient energy can ionize a gas that becomes the fourth state of matter, called plasma. Many studies using the VHP method have used a plasma added (no-touch automated) system called hydrogen peroxide gas plasma (HPGP) to aid in the removal of $\mathrm{H}_{2} \mathrm{O}_{2}$ residues. HPGP sterilization system was the most used sterilizers in U.S. hospitals according to the Boiano and Steege's survey and it was noted that HPGP is not environmentally damaging (i.e., hydrogen peroxide vapor breaks down to water and oxygen after disinfection which is also applied to the HPV method), and it is time 


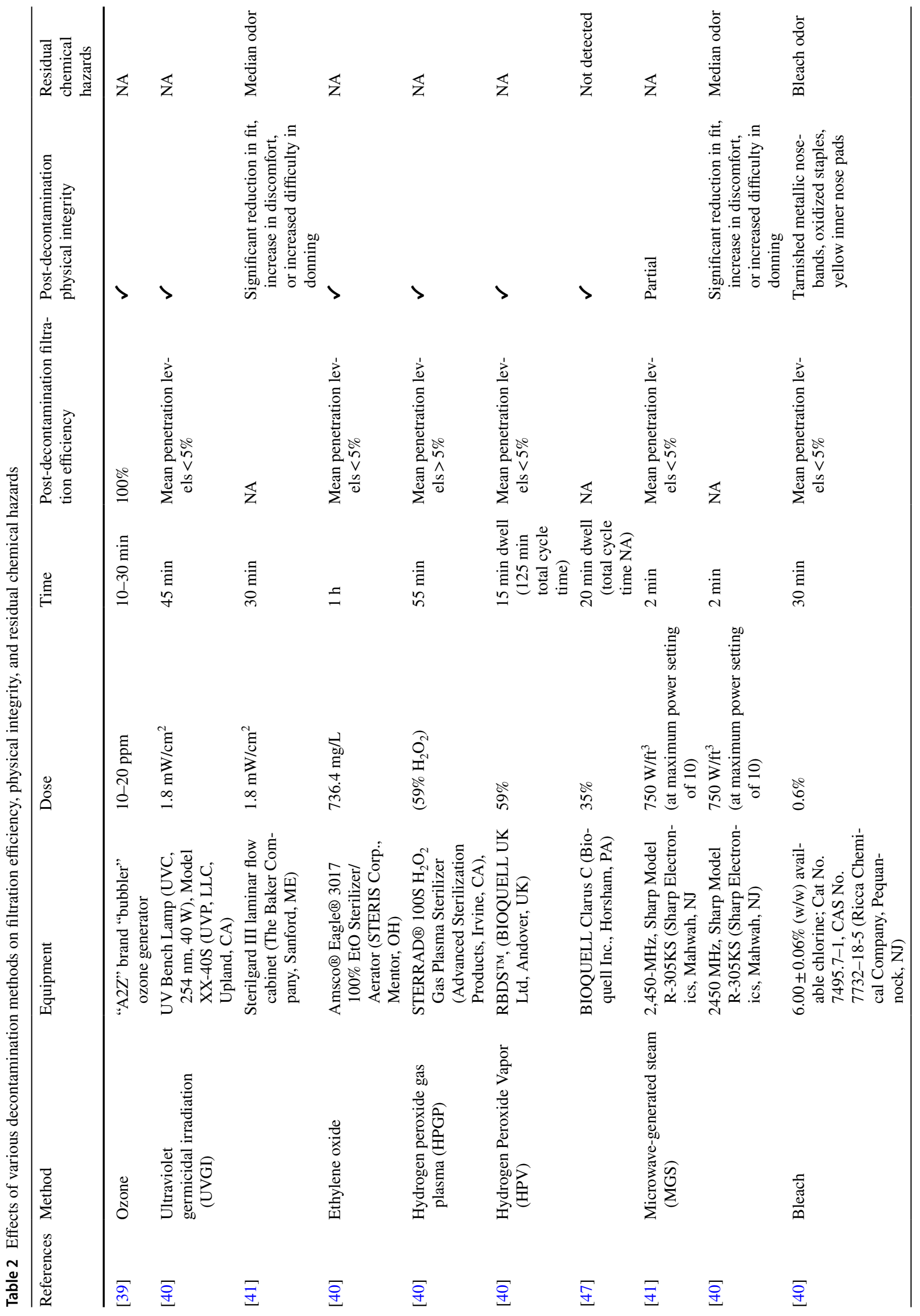




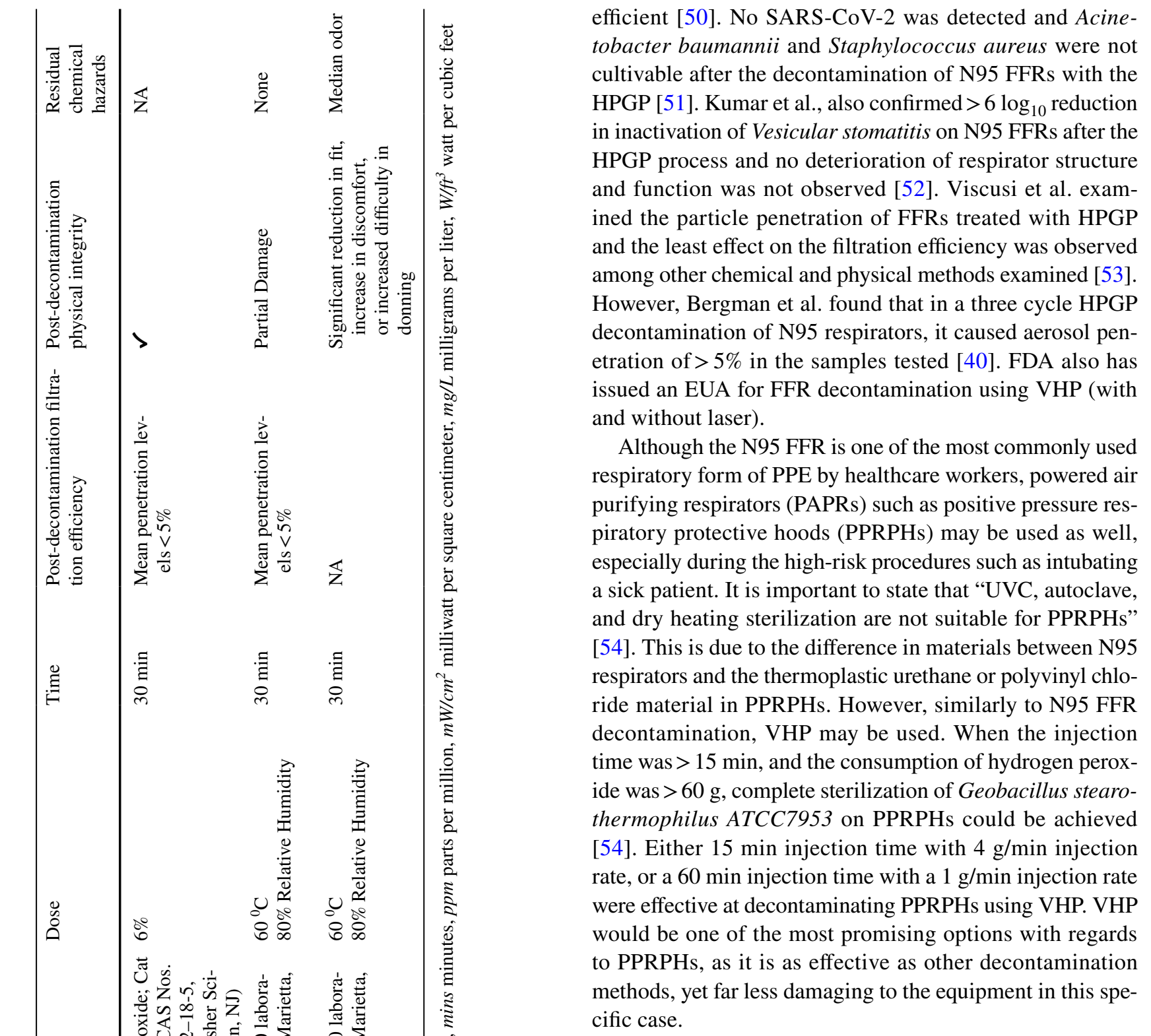

\section{Conclusion}

Evidence suggests that disinfecting N95 FFRs using UVGI, MGS, HPV, HPGP, and 70\% or higher ethanol decontamination methods for reuse can be effective. While all of the decontamination methods appear to provide an acceptable degree of biocidal efficacy, the HPV treatment would be the main suggestion of this paper, due to its combination of high decontamination efficacy even after 50 cycles and no reported degradation of filtration efficiency and respirator fit. Some limiting factors include equipment cost (higher than UVGI and MGS), operation time (longer than the others in general), and a need for locating a suitable operating room. 
The FDA EUA was granted to the three decontamination treatments for FFRs including HPV, HPGP, and VHP.

Authors' contributions Jonghwa Oh had the idea for this article, Ravinder Thaper and Brendan Fagen performed the literature search, and all three authors drafted and critically revised the work.

Funding No funding was received to assist with the preparation of this manuscript.

Availability of data and material Data sharing is not applicable to this article as no datasets were generated or analyzed during the current study.

Code availability Not applicable.

\section{Declarations}

Conflict of interest The authors have no conflicts of interest to declare that are relevant to the content of this article.

\section{References}

1. "Coronavirus." (2020). Accessed July 26, 2020, from, https:// www.who.int/westernpacific/health-topics/coronavirus

2. "Transmission characteristics and principles of infection prevention and control," GOV.UK. (2020). Accessed July 26, 2020, from, https://www.gov.uk/government/publications/wuhan-novelcoronavirus-infection-prevention-and-control/transmission-chara cteristics-and-principles-of-infection-prevention-and-control

3. Read, M. C. (2020). EID: High contagiousness and rapid spread of severe acute respiratory syndrome coronavirus 2. Emerging Infectious Diseases, 26, 1470-1477.

4. Thaper, "Food safety amid Coronavirus disease 2019." (2021). Accessed January 14, 2021, from, http://www.cmrpjournal.org/ article . asp? issn $=2352-0817$; year $=2020 ;$ volume $=10 ;$ issue $=6$; spage $=305$; epage $=307$; aulast $=$ Thaper

5. Guan, W., et al. (2020). Clinical characteristics of Coronavirus disease 2019 in China. New England Journal of Medicine, 382(18), 1708-1720. https://doi.org/10.1056/NEJMoa2002032

6. Thaper, R. (2020). Transmission of SARS-CoV-2 through the air. Current Medicine Research and Practice. https://doi.org/10. 1016/j.cmrp.2020.07.005

7. Holshue, M. L., et al. (2020). First case of 2019 novel Coronavirus in the United States. New England Journal of Medicine, 382(10), 929-936. https://doi.org/10.1056/NEJMoa2001191

8. "Home", Johns Hopkins Coronavirus Resource Center. (2021). Accessed January 18, 2021, from https://coronavirus.jhu.edu/

9. Szeinuk, J., Beckett, W. S., Clark, N., \& Hailoo, W. L. (2000). Medical evaluation for respirator use. Am J Ind Med, 37(1), 142157. https://doi.org/10.1002/(sici)1097-0274(200001)37:1<142:: aid-ajim11>3.0.co;2-k

10. Gosch, M. E., Shaffer, R. E., Eagan, A. E., Roberge, R. J., Davey, V. J., \& Radonovich, L. J. (2013). B95: A new respirator for health care personnel. American Journal of Infection Control, 41(12), 1224-1230. https://doi.org/10.1016/j.ajic.2013.03.293

11. SARS. (2021). Clinical Guidance on Use of Respirators for Prevention CDC. Accessed January 22, 2021, from, https://www.cdc. gov/sars/clinical/respirators.html
12. NIOSH Guide to the Selection and Use of Particulate Respirators. (1996). Accessed 18 Jan 2021, from, https://www.cdc.gov/niosh/ docs/96-101/default.html

13. 42 CFR 84.181. (2009). Non-powered air-purifying particulate filter efficiency level determination. Accessed 18 Jan 2021, from, https://www.govinfo.gov/content/pkg/CFR-2009-title42-vol1/pdf/ CFR-2009-title42-vol1-sec84-181.pdf

14. Respiratory Protection. (2021). 1910.134 Occupational Safety and Health Administration. Accessed January 18, 2021, from, https://www.osha.gov/pls/oshaweb/owadisp.show_document?p_ id $=12716 \&$ p_table $=$ standards

15. C. for D. and R. Health. (2021). Enforcement Policy for Face Masks and Respirators During the Coronavirus Disease (COVID19) Public Health Emergency (Revised), U.S. Food and Drug Administration, July 10, 2020. Accessed January 19, 2021, from, https://www.fda.gov/regulatory-information/search-fda-guida nce-documents/enforcement-policy-face-masks-and-respiratorsduring-coronavirus-disease-covid-19-public-health

16. Committee on the Development of Reusable Facemasks for Use During an Influenza Pandemic, Institute of Medicine, Board on Health Sciences Policy. (2006). Reusability of Facemasks During an Influenza pandemic: Facing the Flu. National Academies Press.

17. CDC. (2021). Healthcare Workers, Centers for Disease Control and Prevention, February 11, 2020. Accessed January 19, 2021, from, https://www.cdc.gov/coronavirus/2019-ncov/hcp/ppe-strat egy/decontamination-reuse-respirators.html

18. Coulliette, A. D., Perry, K. A., Edwards, J. R., \& Noble-Wang, J. A. (2013). Persistence of the 2009 Pandemic Influenza A (H1N1) Virus on N95 Respirators. Applied and Environment Microbiology, 79(7), 2148-2155. https://doi.org/10.1128/AEM.03850-12

19. Ranney, M. L., Griffeth, V., \& Jha, A. K. (2020). Critical supply shortages: The need for ventilators and personal protective equipment during the Covid-19 pandemic. New England Journal of Medicine, 382(18), e41. https://doi.org/10.1056/NEJMp2006141

20. Rubio-Romero, J. C., del Pardo-Ferreira, M. C., Torrecilla-García, J. A., \& Calero-Castro, S. (2020). Disposable masks: Disinfection and sterilization for reuse, and non-certified manufacturing, in the face of shortages during the COVID-19 pandemic. Safety Science, 129, 104830. https://doi.org/10.1016/j.ssci.2020.104830

21. Mills, D., Harnish, D. A., Lawrence, C., Sandoval-Powers, M., \& Heimbuch, B. K. (2018). Ultraviolet germicidal irradiation of influenza-contaminated N95 filtering facepiece respirators. American Journal of Infection Control, 46(7), e49-e55. https://doi.org/ 10.1016/j.ajic.2018.02.018

22. Heimbuch, B. K., et al. (2011). A pandemic influenza preparedness study: Use of energetic methods to decontaminate filtering facepiece respirators contaminated with $\mathrm{H} 1 \mathrm{~N} 1$ aerosols and droplets. American Journal of Infection Control, 39(1), e1-9. https:// doi.org/10.1016/j.ajic.2010.07.004

23. Lin, T.-H., Tang, F.-C., Hung, P.-C., Hua, Z.-C., \& Lai, C.-Y. (2018). Relative survival of Bacillus subtilis spores loaded on filtering facepiece respirators after five decontamination methods. Indoor Air. https://doi.org/10.1111/ina.12475

24. Lore, M. B., Heimbuch, B. K., Brown, T. L., Wander, J. D., \& Hinrichs, S. H. (2012). Effectiveness of three decontamination treatments against influenza virus applied to filtering facepiece respirators. Annals of Occupational Hygiene, 56(1), 92-101. https://doi.org/10.1093/annhyg/mer054

25. Cadnum, J. L., Li, D. F., Redmond, S. N., John, A. R., Pearlmutter, B., \& Donskey, C. J. (2020). Effectiveness of Ultraviolet-C Light and a High-Level Disinfection Cabinet for Decontamination of N95 Respirators. Pathogens and Immunity, 5(1), 52-67. https:// doi.org/10.20411/pai.v5i1.372

26. Fisher, E. M., Williams, J. L., \& Shaffer, R. E. (2011). Evaluation of microwave steam bags for the decontamination of filtering 
facepiece respirators. PLoS ONE, 6(4), e18585. https://doi.org/10. 1371/journal.pone.0018585

27. Goyal, S. M., Chander, Y., Yezli, S., \& Otter, J. A. (2014). Evaluating the virucidal efficacy of hydrogen peroxide vapour. Journal of Hospital Infection, 86(4), 255-259. https://doi.org/10.1016/j. jhin.2014.02.003

28. Tuladhar, E., Terpstra, P., Koopmans, M., \& Duizer, E. (2012). Virucidal efficacy of hydrogen peroxide vapour disinfection. Journal of Hospital Infection, 80(2), 110-115. https://doi.org/10. 1016/j.jhin.2011.10.012

29. Bentley, K., Dove, B. K., Parks, S. R., Walker, J. T., \& Bennett, A. M. (2012). Hydrogen peroxide vapour decontamination of surfaces artificially contaminated with norovirus surrogate feline calicivirus. Journal of Hospital Infection, 80(2), 116-121. https:// doi.org/10.1016/j.jhin.2011.10.010

30. Zonta, W., Mauroy, A., Farnir, F., \& Thiry, E. (2016). Virucidal efficacy of a hydrogen peroxide nebulization against murine norovirus and feline calicivirus, two surrogates of human norovirus. Food and Environmental Virology, 8(4), 275-282. https://doi.org/ 10.1007/s12560-016-9253-5

31. Pottage, T., Richardson, C., Parks, S., Walker, J. T., \& Bennett, A. M. (2010). Evaluation of hydrogen peroxide gaseous disinfection systems to decontaminate viruses. Journal of Hospital Infection, 74(1), 55-61. https://doi.org/10.1016/j.jhin.2009.08.020

32. Kampf, G., Todt, D., Pfaender, S., \& Steinmann, E. (2020). Persistence of coronaviruses on inanimate surfaces and their inactivation with biocidal agents. Journal of Hospital Infection, 104(3), 246-251. https://doi.org/10.1016/j.jhin.2020.01.022

33. Rabenau, H. F., Kampf, G., Cinatl, J., \& Doerr, H. W. (2005). Efficacy of various disinfectants against SARS coronavirus. Journal of Hospital Infection, 61(2), 107-111. https://doi.org/10.1016/j. jhin.2004.12.023

34. Siddharta, A., et al. (2017). Virucidal activity of world health organization-recommended formulations against enveloped viruses, including Zika, Ebola, and emerging Coronaviruses. Journal of Infectious Diseases, 215(6), 902-906. https://doi.org/ 10.1093/infdis/jix046

35. Rabenau, H. F., Cinatl, J., Morgenstern, B., Bauer, G., Preiser, W., \& Doerr, H. W. (2005). Stability and inactivation of SARS coronavirus. Medical Microbiology and Immunology (Berlin), 194(1), 1-6. https://doi.org/10.1007/s00430-004-0219-0

36. Saknimit, M., Inatsuki, I., Sugiyama, Y., \& Yagami, K. (1988). Virucidal efficacy of physico-chemical treatments against Coronaviruses and parvoviruses of laboratory animals. Experimental Animals, 37(3), 341-345. https://doi.org/10.1538/expanim1978. 37.3_341

37. Heimbuch, B. K., Kinney, K., Lumley, A. E., Harnish, D. A., Bergman, M., \& Wander, J. D. (2014). Cleaning of filtering facepiece respirators contaminated with mucin and Staphylococcus aureus. American Journal of Infection Control, 42(3), 265-270. https://doi.org/10.1016/j.ajic.2013.09.014

38. Subhash, S. S., et al. (2014). Effectiveness of common healthcare disinfectants against H1N1 influenza virus on reusable elastomeric respirators. Infection Control and Hospital Epidemiology, 35(7), 894-897. https://doi.org/10.1086/676863

39. Dennis, R., Pourdeyhimi, B., Cashion, A., Emanuel, S., \& Hubbard, D. (2020). Durability of disposable N95 mask material when exposed to improvised ozone gas disinfection. The Journal of Science and Medicine. https://doi.org/10.37714/josam.v2i1.37

40. Bergman, M. S., Viscusi, D. J., Heimbuch, B. K., Wander, J. D., Sambol, A. R., \& Shaffer, R. E. (2010). Evaluation of multiple
(3-Cycle) decontamination processing for filtering facepiece respirators. Journal of Engineered Fibers and Fabrics, 5(4), 155892501000500400. https://doi.org/10.1177/155892501000500 405

41. Viscusi, D. J., et al. (2011). Impact of three biological decontamination methods on filtering facepiece respirator fit, odor, comfort, and donning ease. Journal of Occupational and Environmental Hygiene, 8(7), 426-436. https://doi.org/10.1080/15459624.2011. 585927

42. Lin, T.-H., Chen, C.-C., Huang, S.-H., Kuo, C.-W., Lai, C.-Y., \& Lin, W.-Y. (2017). Filter quality of electret masks in filtering 14.6-594 nm aerosol particles: Effects of five decontamination methods. PLoS ONE, 12(10), e0186217. https://doi.org/10.1371/ journal.pone.0186217

43. Huang, S.-H., Chen, C.-W., Kuo, Y.-M., Lai, C.-Y., McKay, R., \& Chen, C.-C. (2013). Factors affecting filter penetration and quality factor of particulate respirators. Aerosol and Air Quality Research, 13(1), 162-171. https://doi.org/10.4209/aaqr.2012.07.0179

44. Donat, T. (2020). Omnidirectional Ultraviolet (UVC) Chamber Irradiation for Crisis Decontamination and Reuse of Select Personal Protective Equipment. JAMA, 323(19), 1911. https://doi.org/ 10.1001/jama.2020.4770

45. Fischer, R. J., et al. (2020). Assessment of N95 respirator decontamination and re-use for SARS-CoV-2. medrxiv. https://doi.org/ 10.1101/2020.04.11.20062018

46. Bergman, M. S., Viscusi, D. J., Palmiero, A. J., Powell, J. B., \& Shaffer, R. E. (2011). Impact of three cycles of decontamination treatments on filtering facepiece respirator fit. Journal of the International Society for Respiratory Protection, 28(1), 12.

47. Schwartz, A., et al. (2020). Decontamination and reuse of N95 respirators with hydrogen peroxide vapor to address worldwide personal protective equipment shortages during the SARS-CoV-2 (COVID-19) pandemic. Applied Biosafety, 25(2), 67-70. https:// doi.org/10.1177/1535676020919932

48. Grossman, J., et al. (2020). Institution of a novel process for N95 respirator disinfection with vaporized hydrogen peroxide in the setting of the COVID-19 pandemic at a large academic medical center. Journal of the American College of Surgeons, 231(2), 275-280. https://doi.org/10.1016/j.jamcollsurg.2020.04.029

49. Kenney, P. A., et al. (2020). Hydrogen peroxide vapor sterilization of N95 respirators for reuse. medRxiv. https://doi.org/10.1101/ 2020.03.24.20041087

50. Boiano, J. M., \& Steege, A. L. (2015). Ethylene oxide and hydrogen peroxide gas plasma sterilization: precautionary practices in U.S. hospitals. Zentralsterilisation Wiesb., 23(4), 262-268.

51. Ibáñez-Cervantes, G., et al. (2020). Disinfection of N95 masks artificially contaminated with SARS-CoV-2 and ESKAPE bacteria using hydrogen peroxide plasma: Impact on the reutilization of disposable devices. American Journal of Infection Control, 48(9), 1037-1041. https://doi.org/10.1016/j.ajic.2020.06.216

52. Kumar, A., et al. (2020). N95 mask decontamination using standard hospital sterilization technologies. medRxiv. https://doi.org/10. $1101 / 2020.04 .05 .20049346$

53. Viscusi, D. J., et al. (2007). Effect of decontamination on the filtration efficiency of two filtering facepiece respirator models. International Society for Respiratory Protection, 24, 93-107.

54. Hao, L., et al. (2019). Disinfection efficiency of positive pressure respiratory protective hood using fumigation sterilization cabinet. Biosafety and Health, 1(1), 46-53. https://doi.org/10.1016/j. bsheal.2019.02.006 